\title{
Cost Stickiness: Analysis and Determinants. Case Study of Saudi Companies
}

\author{
Tazarki Walid \\ Department of Accounting, College of Business, University of Jeddah, Jeddah, Saudi Arabia \\ Email: tazarkiwalid@gmail.com
}

How to cite this paper: Walid, T. (2021) Cost Stickiness: Analysis and Determinants. Case Study of Saudi Companies. Theoretical Economics Letters, 11, 239-248. https://doi.org/10.4236/tel.2021.112017

Received: February 25, 2021

Accepted: April 9, 2021

Published: April 12, 2021

Copyright $\odot 2021$ by author(s) and Scientific Research Publishing Inc. This work is licensed under the Creative Commons Attribution International License (CC BY 4.0).

http://creativecommons.org/licenses/by/4.0/

\begin{abstract}
This paper examines the existence of cost stickiness of KSA firms using the $A B J$ model. By analyzing accounting data of 12 selected Saudi companies from 2010 to 2019, the results show the existence of cost stickiness in COGS more than SGA Expenses. Furthermore, a low level of debts and a high CashFlow ratio are associated with cost stickiness in Saudi companies.
\end{abstract}

\section{Keywords}

Cost Stickiness, Selling, General and Administrative Costs, Cost of Goods Sold, Cost Behavior, Saudi Companies

\section{Introduction}

Nowadays, the world is characterized by the globalization of markets and the relentless growth of competition between companies. Therefore, decision-makers should be properly informed about the behavior of costs. Recent studies focusing on cost behavior have found that costs increase more with increases in activity than they decrease in response to equivalent decreases in activity; this result is called cost stickiness. This cost stickiness is in contradiction with the traditional theory of cost behavior which specifies that costs behave the same behavior for activity increases and decreases.

The problem proposed in this study is to know whether Selling, General and Administrative expenses (SGA) and/or Cost of Goods Sold (COGS) are sticky to changes in sales level? Thereafter, if cost stickiness exists, which factors can explain it?

Several studies have focused on the study of cost stickiness in developed and developing countries. However, we can notice an enormous lack of studies focusing on GCC (Gulf Cooperation Council) countries, more precisely researches 
on Saudi firms. The Kingdom of Saudi Arabia is ranked among the richest countries in the world (a member of the G20 and the first producer of oil). Saudi companies are characterized by their large size, high turnover, and economic power on domestic and global economy.

This research was motivated by this idea, so we're trying to provide more answers on the degree of cost stickiness in Saudi companies and searching for reasons that can explain this economic phenomenon.

The paper is organized as follows. Section 2 is a brief review of literature about analysis of cost stickiness; Section 3 describes the methodology; Section 4 provides results. Concluding comments are set out in Section 5 .

\section{Literature Review}

Pioneers papers about cost behavior are provided by Noreen, Noreen and Soderstrom (1994) who confirm that overhead costs are not proportional to activity levels. After then, Anderson, Banker, and Janakiraman (2003) (henceforth ABJ) working papers show that cost increases more when activity rises than decreases less when activity falls by an equivalent amount. The authors label this type of cost behavior as "cost stickiness". Based on Anderson et al. (2003) model, several studies examine different phenomenon of "sticky costs" and develop the extant literature in this area.

In their paper, Noreen, Noreen and Soderstrom (1994) indicated that in terms of activity level, costs are divided into fixed and variable. Variable costs change in proportion to changes in activity level. Therefore, if costs do not increase in proportion to sales, then it is considered mismanagement by analyzers.

Anderson et al. (2003) were the first who used the term stickiness of costs to describe asymmetric reaction of costs and their analysis of general, administrative and selling costs supported it. They studied differential slopes of costs and found that increases in costs are more when sales increase than decreases in costs when sales decrease because the slope is smaller when there is decreased level of activity and it is said that costs are sticky.

Using a sample of US, UK, French, and German firms, Calleja et al. (2006) find that operating costs are sticky in response to changes in revenues. Furthermore, the authors indicated costs of French and German firms are more sticky than costs of UK and US firms.

However, Weiss (2010) indicated that costs are considered as "anti-sticky" if they rise less in response to sales increases than they fall when sales decrease equally.

Studying Chinese manufacturing firms from 2008 to 2011, Xu et al. (2014) found total costs, operating costs and general \& administrative expenses are sticky but Selling expenses are anti-sticky.

Abu-Serdaneh (2014) investigated the asymmetrical behavior of cost in Jordan context, the author found anti sticky cost behavior for the cost of goods sold, and selling expenses, while the cost behavior for SGA, and Administration costs is found to be symmetric, exhibiting neither stickiness nor anti stickiness. 
In their study, Bugeja et al. (2014) used a large sample of Australian firms, they found cost behavior in Australian firms is sticky on average, moreover, the degree of cost stickiness in Australia increases with a firm's asset and employee intensity.

To examine the sticky cost behavior of manufacturing companies listed in Indonesia Stock Exchange, Zulfiati et al. (2019) used also ABJ model. The results show that employee intensity ratio and firm size variable affect the degree of cost stickiness, however, capital intensity ratio and free cash flow do not affect the degree of cost stickiness.

Recent studies focus on the relationship between cost stickiness and other economic events. Hassanein and Younis (2020) examined the stickiness behaviors of UK firm costs pre, during, and post the period of the financial crisis. They found that total costs have behaved as sticky pre the financial crisis and anti-sticky during and post the financial crisis. Furthermore, cost of goods sold has changed from sticky (pre and during the financial crisis) to anti-sticky (post the financial crisis).

\section{Methodology}

This section will present hypotheses to be tested, the model to be estimated, variables and data used.

\subsection{Hypotheses}

To respond to the problem proposed in this study, eight hypotheses will be examined. From the basic research of ABJ (2003), the first hypothesis (H1) will be tested, we're trying to find out if SGA costs are sticky to changes in sales. Other authors such as Subramaniam and Weidenmier (2003), Xu et al. (2014) and He (2014) have used COGS as an independent variable in their models, this idea motivated our second hypothesis (H2) by testing whether COGS can explain cost stickiness in sales.

In order to explain the degree of cost stickiness in sales, the hypotheses from H3 to H8 will be tested. Many authors such as Calleja et al. (2006) have tested firm size (total assets), assuming that large firms may suffer from cost stickiness, this idea will be tested by hypotheses H3 and H4. Research provided by Subramaniam \& Weidenmier (2003) and Via and Perego (2013) supported the idea that firms with a high degree of debt are less exposed to the risk of cost stickiness, in this paper hypotheses $\mathrm{H} 5$ and $\mathrm{H} 6$ take this idea into account. Chen et al. (2012) and Banker et al. (2011) suggested that a low level of cash flow is related to a reduction in costs, to study this idea, hypotheses $\mathrm{H} 7$ and $\mathrm{H} 8$ will be tested.

\footnotetext{
H1: Selling, General and Administrative costs (SGA) are sticky to changes in sales level. For acceptance of this hypothesis, in model (1.a) $\beta_{1}$ should be $>0$ and $\beta_{2}<0$.

$\mathrm{H} 2$ : Cost of Goods Sold (COGS) is sticky to changes in sales level. For acceptance of this hypothesis, in model (1.b) $\beta_{1}$ should be $>0$ and $\beta_{2}<0$.
} 


\section{Continued}

H3: Stickiness of SGA is higher in companies with higher level of total assets. For acceptance of this hypothesis, in model (2.a) $\beta_{1}$ should be $>0, \boldsymbol{\beta}_{2}<0$ and $\boldsymbol{\beta}_{4}<0$.

H5: Stickiness of SGA is lower in companies with higher level of total debts. For acceptance of this hypothesis, in model (2.a) $\beta_{1}$ should be $>0, \beta_{2}<0$ and $\beta_{5}>0$.

H7: Stickiness of SGA is higher in companies with higher level of total cash-flow. For acceptance of this hypothesis, in model (2.a) $\beta_{1}$ should be $>0, \beta_{2}<0$ and $\beta_{6}<0$.

\subsection{Model}

This paper test for cost stickiness of Saudi companies using the ABJ model:

$$
\log \left[\frac{\text { Costs }_{i, t}}{\text { Costs }_{i, t-1}}\right]=\beta_{0}+\beta_{1} \log \left[\frac{\text { Revenue }_{i, t}}{\text { Revenue }_{i, t-1}}\right]+\beta_{2} d_{i, t} \log \left[\frac{\text { Revenue }_{i, t}}{\text { Revenue }_{i, t-1}}\right]+\varepsilon_{i, t}
$$

The variable $d$ is a dummy variable that takes the value of 1 when revenue decreases between two periods and is otherwise 0 .

The log model is used in a lot of previous studies like Anderson et al., (2003) and Subramaniam and Weidenmier (2003). Since the value of the dummy variable $(d)$ is 0 when revenue increases, $\beta_{1}$ measures the increase in percentage terms in costs with a $1 \%$ increase in revenue. However, since the value of the dummy variable $(d)$ is 1 when revenue decreases, the sum of $\beta_{1}$ and $\beta_{2}$ measures the decrease, in percentage terms, in costs following a $1 \%$ decrease in revenue. The traditional cost behavior model is valid when $\beta_{2}$ is equal to 0 since upward and downward changes in costs will be equal, and $\beta_{1}$ would be equal to 1 , reflecting proportionality. Otherwise, companies present sticky cost behavior when $\beta_{2}$ is negative and statistically significant.

The dependent variable Cost $_{i, t}$ will be replaced by Selling, General and Administrative expenses (SGA) and Cost of Goods Sold (COGS) in model (1.a) and (1.b) respectively. The model (1) will be written as follow:

$$
\begin{aligned}
& \log \left[\frac{\mathrm{SGA}_{i, t}}{\mathrm{SGA}_{i, t-1}}\right]=\beta_{0}+\beta_{1} \log \left[\frac{\text { Revenue }_{i, t}}{\text { Revenue }_{i, t-1}}\right]+\beta_{2} d_{i, t} \log \left[\frac{\text { Revenue }_{i, t}}{\text { Revenue }_{i, t-1}}\right]+\varepsilon_{i, t} \\
& \log \left[\frac{\text { COGS }_{i, t}}{\text { SGA }_{i, t-1}}\right]=\beta_{0}+\beta_{1} \log \left[\frac{\text { Revenue }_{i, t}}{\text { Revenue }_{i, t-1}}\right]+\beta_{2} d_{i, t} \log \left[\frac{\text { Revenue }_{i, t}}{\text { Revenue }_{i, t-1}}\right]+\varepsilon_{i, t}
\end{aligned}
$$

\section{$\underline{A B J \text { extension }}$}

In a second step, the ABJ Model will be extended to include variables that can affect changes in sales revenue in response to cost changes. 


$$
\begin{aligned}
\log \left[\frac{\text { Costs }_{i, t}}{\text { Costs }_{i, t-1}}\right]= & \beta_{0}+\beta_{1} \log \left[\frac{\text { revenue }_{i, t}}{\text { revenue }_{i, t-1}}\right]+\beta_{2} d_{i, t} \log \left[\frac{\text { revenue }_{i, t}}{\text { revenue }_{i, t-1}}\right] \\
& +\beta_{3} d_{i, t} \log \left[\frac{\text { revenue }_{i, t}}{\text { revenue }_{i, t-1}}\right] * \log \left[\frac{\text { Assets }_{i, t}}{\text { revenue }_{i, t}}\right] \\
& +\beta_{4} d_{i, t} \log \left[\frac{\text { revenue }_{i, t}}{\text { revenue }_{i, t-1}}\right] * \log \left[\frac{\text { Debts }_{i, t}}{\text { revenue }_{i, t}}\right] \\
& +\beta_{5} d_{i, t} \log \left[\frac{\text { revenue }_{i, t}}{\text { revenue }_{i, t-1}}\right] * \log \left[\frac{\text { FCF }_{i, t}}{\text { revenue }_{i, t}}\right]+\varepsilon_{i, t}
\end{aligned}
$$

where:

$$
\begin{aligned}
& \log \left[\frac{\text { Assets }_{i, t}}{\text { revenue }_{i, t}}\right] \text { is used to measure asset intensity, } \\
& \log \left[\frac{\text { Debts }_{i, t}}{\text { revenue }_{i, t}}\right] \text { is used to measure total debt intensity, } \\
& \log \left[\frac{\mathrm{FCF}_{i, t}}{\text { revenue }_{i, t}}\right] \text { is used to measure free cash flow as a proxy for empire }
\end{aligned}
$$
building incentives.

As done for the model 1, two versions will be considered in model 2. The first includes Selling, General and Administrative expenses (SGA), the second includes Cost of Goods Sold (COGS). The model (2) will be written as follow:

$$
\begin{aligned}
\log \left[\frac{\mathrm{SGA}_{i, t}}{\mathrm{SGA}_{i, t-1}}\right]= & \beta_{0}+\beta_{1} \log \left[\frac{\text { revenue }_{i, t}}{\text { revenue }_{i, t-1}}\right]+\beta_{2} d_{i, t} \log \left[\frac{\text { revenue }_{i, t}}{\text { revenue }_{i, t-1}}\right] \\
& +\beta_{3} d_{i, t} \log \left[\frac{\text { revenue }_{i, t}}{\text { revenue }_{i, t-1}}\right] * \log \left[\frac{\text { Assets }_{i, t}}{\text { revenue }_{i, t}}\right] \\
& +\beta_{4} d_{i, t} \log \left[\frac{\text { revenue }_{i, t}}{\text { revenue }_{i, t-1}}\right] * \log \left[\frac{\text { Debts }_{i, t}}{\text { revenue }_{i, t}}\right] \\
& +\beta_{5} d_{i, t} \log \left[\frac{\text { revenue }_{i, t}}{\text { revenue }_{i, t-1}}\right] * \log \left[\frac{\text { FCF }_{i, t}}{\text { revenue }_{i, t}}\right]+\varepsilon_{i, t}
\end{aligned}
$$

And,

$$
\begin{aligned}
\log \left[\frac{\text { COGS }_{i, t}}{\text { COGS }_{i, t-1}}\right]= & \beta_{0}+\beta_{1} \log \left[\frac{\text { revenue }_{i, t}}{\text { revenue }_{i, t-1}}\right]+\beta_{2} d_{i, t} \log \left[\frac{\text { revenue }_{i, t}}{\text { revenue }_{i, t-1}}\right] \\
& +\beta_{3} d_{i, t} \log \left[\frac{\text { revenue }_{i, t}}{\text { revenue }_{i, t-1}}\right] * \log \left[\frac{\text { Assets }_{i, t}}{\text { revenue }_{i, t}}\right] \\
& +\beta_{4} d_{i, t} \log \left[\frac{\text { revenue }_{i, t}}{\text { revenue }_{i, t-1}}\right] * \log \left[\frac{\text { Debts }_{i, t}}{\text { revenue }_{i, t}}\right] \\
& +\beta_{5} d_{i, t} \log \left[\frac{\text { revenue }_{i, t}}{\text { revenue }_{i, t-1}}\right] * \log \left[\frac{\text { FCF }_{i, t}}{\text { revenue }_{i, t}}\right]+\varepsilon_{i, t}
\end{aligned}
$$




\subsection{Variables}

7 variables will be considered in this paper:

Selling, General and Administrative Expenses (SGA),

Cost of goods sold (COGS),

Sales revenues (Revenues),

Assets intensity (Size): log (Total Assets/Total Revenues),

Debts intensity: log (long-term debts/Total assets),

Free cash-flow: log [(Cash and equivalent + short-term investment)/Total Assets],

Dummy variable $d$ : An indicator variable that equals 1 if sales decrease between two periods, and zero otherwise.

Data are collected from the annual reports of Saudi companies selected in this study. Table 1 presents a statistical description of all the variables used in the sample. Only two companies always indicated increases in sales over 2010-2019, (in other words: dummy variable $d=0$ ). For other companies, the data shows different periods of sales declines $(d=1)$. All amounts in Table 1 are expressed in thousands of SAR (exception for amounts expressed in logarithm).

\subsection{Sample and Estimation}

In this study, the sample is composed of 12 Saudi companies from 2010 to 2019, data are collected from accounting annual reports. Since we focus on the variations in costs and sales between every two periods over [2010-2019], we will have 9 periods to study, this number will be multiplied by 12 (the number of companies studied), therefore we'll have a sample made up of 108 observations. The data used are arranged as a pooled regression model and estimated using Generalized Least Squares. The regressions are carried out using E-Views Application.

Table 1. Descriptive statistics of variables.

\begin{tabular}{ccccc}
\hline & MIN & MAX & Mean & SD \\
\hline SGA expenses & 12445 & 21560955 & 3178480.5 & 707792.8733 \\
COGS & 190050 & 137511488 & 18849788.1 & 3602123.483 \\
Sales & 105897 & 189898253 & 27711496.7 & 4672689.614 \\
Log(SGA t/SGA t - 1) & -0.38664198 & 0.89742483 & 0.08129873 & 0.157553764 \\
Log (COGS t/COGS t -1$)$ & -0.5207813 & 1.72439324 & 0.09720417 & 0.151075449 \\
Log (sales t/sales t -1$)$ & -0.26456436 & 1.29134557 & 0.09093666 & 0.134878503 \\
ASSETS & 1881785 & 337437888 & 75286581.4 & 5271574.877 \\
Log (Assets/Sales) & -0.18166062 & 1.27118318 & 0.52060116 & 0.126429631 \\
LONG term debts & 163272 & 93243524 & 16971096 & 3470426.106 \\
Log (deb/sales) & -4.24917678 & 0.23076436 & -1.11839539 & 0.413458013 \\
CASH-flow & 40719 & 40247740 & 6268939.21 & 643251.5094 \\
Log CF/Sales & -4.90574709 & -1.26778257 & -2.62885704 & 0.482503375 \\
\hline
\end{tabular}




\section{Results}

The results of regression models are provided in Table 2.

In model (1.a) where the dependent variable is SGA expenses, the results indicated $\beta_{1}>0$ (significant at $1 \%$ ) and $\beta_{2}>0$ (but not significant), therefore hypothesis $\mathrm{H} 1$ should be rejected. Selling, General and Administrative costs (SGA) aren't sticky to changes in sales level. However, we can note a slight variation in SGA expenses following a variation in sales. If sales increase by $1 \%$, SGA expenses are increased only by $0.433 \%$. This result isn't consistent with ABJ (2003) who found SGA costs are "sticky", authors reported that SGA costs increase $0.55 \%$ per $1 \%$ increase in sales and decrease only $35 \%$ per $1 \%$ decrease in sales.

In model (1.b) where the dependent variable is COGS, the results indicated $\beta_{1}>0$ (significant at $1 \%$ ) and $\beta_{2}<0$ (significant at $1 \%$ ), therefore hypothesis $\mathrm{H} 2$ is accepted, Cost of Goods Sold (COGS) is sticky to changes in sales level. We note $\beta_{1}=1.1$, which means if sales increase by $1 \%$, COGS increase by $1.1 \%$. On the other hand, $\beta_{1}+\beta_{1}=0.707$, indicating that if sales decrease by $1 \%$, COGS

Table 2. Results of regression models.

\begin{tabular}{|c|c|c|c|c|c|}
\hline \multicolumn{3}{|c|}{$\begin{array}{l}\text { Model 1.a } \\
\text { Dependent Variable is SGA Expenses }\end{array}$} & \multicolumn{3}{|c|}{$\begin{array}{c}\text { Model 1.b } \\
\text { Dependent Variable is COGS }\end{array}$} \\
\hline Variable & Coefficient & t-Statistic & Variable & Coefficient & t-Statistic \\
\hline$\beta_{0}$ & 0.0446 & $2.316^{\star *}$ & $\beta_{0}$ & -0.006059 & -0.474 \\
\hline$\beta_{1}$ & 0.433 & $4.946^{* * *}$ & $\beta_{1}$ & 1.106003 & $19.07^{\star * *}$ \\
\hline$\beta_{2}$ & 0.1126 & 0.375 & $\beta_{2}$ & -0.399513 & $-2.0083^{\star *}$ \\
\hline $\mathbf{R}^{2}$ & 0.257 & & $\mathbf{R}^{2}$ & 0.810658 & \\
\hline $\operatorname{Adj} R^{2}$ & 0.243 & & $\operatorname{Adj} R^{2}$ & 0.807052 & \\
\hline $\mathrm{F}$ & 18.188 & & $\mathrm{~F}$ & 224.7765 & \\
\hline DW & 2.187 & & DW & 2.167003 & \\
\hline \multirow{2}{*}{\multicolumn{3}{|c|}{$\begin{array}{c}\text { Model 2.a } \\
\text { Dependent Variable is SGA Expenses }\end{array}$}} & \multicolumn{3}{|c|}{ Model 2.b } \\
\hline & & & \multicolumn{3}{|c|}{ Dependent Variable is COGS } \\
\hline Variable & Coefficient & $\mathrm{t}$-Statistic & Variable & Coefficient & $\mathrm{t}$-Statistic \\
\hline$\beta_{0}$ & 0.048 & $2.584^{\star *}$ & $\beta_{0}$ & -0.0012 & -0.1005 \\
\hline$\beta_{1}$ & 0.423 & $5.009^{\star * *}$ & $\beta_{1}$ & 1.092 & $20.03^{\star * *}$ \\
\hline$\beta_{2}$ & -1.639 & -1.387 & $\beta_{2}$ & -1.865 & $-2.444^{\star *}$ \\
\hline$\beta_{3}$ & 0.825 & 1.476 & $\beta_{3}$ & 0.269 & 0.746 \\
\hline$\beta_{4}$ & 0.396 & $2.582^{\star *}$ & $\beta_{4}$ & 0.263 & $2.653^{\star * *}$ \\
\hline$\beta_{5}$ & -0.713 & $-2.035^{\star *}$ & $\beta_{5}$ & -0.728 & $-3.2183^{\star * *}$ \\
\hline $\mathbf{R}^{2}$ & 0.331 & & $\mathbf{R}^{2}$ & 0.837 & \\
\hline $\operatorname{Adj} R^{2}$ & 0.298 & & $\operatorname{Adj} R^{2}$ & 0.83 & \\
\hline F & 10.125 & & $\mathrm{~F}$ & 105.51 & \\
\hline DW & 2.4029 & & DW & 2.072 & \\
\hline
\end{tabular}

${ }^{*},{ }^{* *},{ }^{* *}$ indicate significance at $10 \%, 5 \%$, and $1 \%$ respectively. 
decrease only by $0.707 \%$, proving the existence of cost stickiness. Subramanian and Weidenmier (2003) found SGA costs and COGS are both sticky when revenues changes exceed $10 \%$. A similar result was provided by He who found SGA costs and COGS are sensitive to changes in sales in a period of recession.

By comparing the two models (1.a) and (1.b), the results show Adj $\mathrm{R}^{2}=0.243$ and 0.807 respectively, and F-Stat $=18.18$ and 224.7 respectively, we can state that the model (1.b) is more significant than the model (1.a) and there is strong evidence of cost stickiness for COGS than SGA expenses in Saudi companies. An opposite result was found by Nassirzadeh et al. (2013) in a context of firms in Iran, the authors suggested that COGS is not sticky to variations in sales whereas SGA costs are sticky.

In a second step, Model 1 was extended to include other variables that may explain the existence of cost stickiness. Thus, Model 2 includes 3 other variables: Assets, Debts and Cash-flow. Two versions were also tested, model (2.a) where the dependent variable is SGA expenses and model (2.b) where the dependent variable is COGS.

In model (2.a), we notice that $\beta_{1}>0$ (significant at $1 \%$ ) and $\beta_{2}<0$ (but not significant), therefore, hypothesis $\mathrm{H} 1$ is rejected once again, there is no cost stickiness for SGA expenses in Saudi companies. Since $\beta_{2}$ is insignificant, therefore, hypotheses H3, H5 and H7 can't be accepted. However, it should be noted that $\beta_{4}$ (Debts) and $\beta_{5}(\mathrm{CF})$ are significant in this regression.

In model (2.b), the results indicated $\beta_{1}>0$ (significant at $1 \%$ ) and $\beta_{2}<0$ (significant at $5 \%$ ), again, hypothesis $\mathrm{H} 2$ is confirmed, COGS is sticky to changes in sales level in our study. However, the regressions showed $\beta_{3}$ (Assets) is not significant, thus $\mathrm{H} 4$ was rejected, so we can't affirm if the size of the companies can affect stickiness of COGS. Nassirzadeh et al. (2013) also confirm this result for Iranian firms indicating that firm size does not affect the degree of stickiness of these costs. However, in a case study from Australia, Bugeja et al. (2014) found the size of Australian firms is consistent with the degree of cost stickiness.

The regression of model (2.b) showed $\beta_{4}=0.263$ (significant at $1 \%$ ), thus, hypothesis $\mathrm{H6}$ is accepted, indicating that more companies are in debts less they suffer from cost stickiness. This result is similar to Calleja et al. (2006) results. By making some international comparisons, the authors have empirically proved empirically that a high level of debt was associated with a low level of cost stickiness for US, German and French companies.

Finally, we find $\beta_{5}=-0.728$ (significant at $1 \%$ ), therefore $\mathrm{H} 8$ hypothesis is accepted, a high level of CF is associated with cost stickiness in COGS. The same result has been proved by Abu-Serdaneh (2014) who found a low level of cash flow is associated with a low degree of cost stickiness for companies in Jordan.

In summary, we can conclude that the hypotheses $\mathrm{H} 2, \mathrm{H} 6$ and $\mathrm{H} 8$ are accepted, while the hypotheses H1, H3, H4, H5 and H7 are rejected. For Saudi companies, cost stickiness is more evident for COGS than SGA expenses. Results show more companies are in debt less they suffer from cost stickiness, however, 
more companies have a high CF ratio more they are exposed to cost stickiness.

\section{Conclusion}

The objective of this study was to study cost stickiness in a sample composed of Saudi companies. The sample used is composed by 12 Saudi companies and the data cover period from 2010 to 2019. The ABJ model was adopted under two versions. First model attempts to examine cost stickiness of SGA expenses and COGS. The results showed the existence of cost stickiness in COGS more than SGA Expenses. Second model tries to extend the first by using variables susceptible to explain cost stickiness. The results indicated that a low level of debts and a high Cash-Flow ratio are associated with cost stickiness in Saudi companies. The forthcoming studies may focus on an international comparison of cost stickiness between GCC companies.

\section{Conflicts of Interest}

The author declares no conflicts of interest regarding the publication of this paper.

\section{References}

Abu-Serdaneh, J. (2014). The Asymmetrical Behavior of Cost: Evidence from Jordan. International Business Research, 7, 113-122. https://doi.org/10.5539/ibr.v7n8p113

Anderson, M. C., Banker, R. D., \& Janakiraman, S. N. (2003). Are Selling, General, and Administrative Costs "Sticky"? Journal of Accounting Research, 41, 47-63. https://doi.org/10.1111/1475-679X.00095

Banker, R., Byzalov, D., \& Plehn-Dujowich, J. M. (2011). Sticky Cost Behavior: Theory and Evidence. Working Paper, Philadelphia, PA: Temple University. https://doi.org/10.2139/ssrn.1659493

Bugeja, M., Lu, M., \& Shan, Y. (2014). Cost Stickiness in Australia: Characteristics and Determinants. Australian Accounting Review, 25, 248-261. https://doi.org/10.1111/auar.12066

Calleja, K., Steliaros, M., \& Thomas, D. C. (2006). A Note on Cost Stickiness: Some International Comparisons. Management Accounting Research, 17, 127-140. https://doi.org/10.1016/j.mar.2006.02.001

Chen, C. X., Lu, H., \& Sougiannis, T. (2012). The Agency Problem, Corporate Governance, and the Asymmetrical Behavior of Selling, General, and Administrative Costs. Contemporary Accounting Research, 29, 252-282. https://doi.org/10.1111/j.1911-3846.2011.01094.x

Hassanein, A., \& Younis, M. (2020). Cost Stickiness Behavior and Financial Crisis: Evidence from the UK Chemical Industry. Corporate Ownership \& Control, 17, 46-56. https://doi.org/10.22495/cocv17i2art4

He, H. H. (2014). Cost Behavior of Selling, General, and Administrative Costs and Cost of Goods Sold during Economic Recession. Research in Business and Economics Journal, $10,1-9$.

Nassirzadeh, F., Saei, M. J., Salehi, M., \& Bayegi, S. A. H. (2013). A Study of the Stickiness of Cost of Goods Sold and Operating Costs to Changes in Sales Level in Iran. Studies in 
Business and Economics, Lucian Blaga University of Sibiu, Faculty of Economic Sciences, 8, 79-89.

Noreen, E., Noreen, E., \& Soderstrom, N. (1994). Are Overhead Costs Strictly Proportional to Activity? Journal of Accounting and Economics, 17, 255-278. https://doi.org/10.1016/0165-4101(94)90012-4

Subramanian, C., \& Weidenmier, M. L. (2003). Additional Evidence on the Sticky Behavior of Costs. Working Paper. https://doi.org/10.2139/ssrn.369941

Via, N. D., \& Perego, P. (2013). Sticky Cost Behavior: Evidence from Small and Medium Sized Companies. Accounting \& Finance, 54, 753-778.

Weiss, D. (2010). Cost Behavior and Analysts' Earnings Forecasts. The Accounting Review, 85, 1441-1471. https://doi.org/10.2308/accr.2010.85.4.1441

Xu, L.-Y., Wang, F.-J., \& Hu, Y.-H. (2014). Empirical Research of Costs Stickiness Behavior in Chinese Manufacturing Listed Firms. 5th International Asia Conference on Industrial Engineering and Management Innovation (IEMI 2014), Volume 1, 359-363.

Zulfiati, L., Gusliana, R., \& Nuridah, S. (2019). Cost Stickiness: Behavior and Factors. In Annual International Conference on Accounting Research (AICAR 2019) (pp. 143-145). Paris: Atlantis Press. 